ISSN electrónico: 2172-9077

DOI: https://doi.org/10.14201/fjc2019198797

\title{
Cinema eXPANDido PORTuguês dO SÉc. XXI
}

\section{Portuguese Expanded Cinema of the $21^{\text {th }}$ Century}

\author{
Prof. Doutor Paulo CUNHA \\ Professor Auxiliar \\ Universidade da Beira Interior, Portugal \\ E-mail: pmfcunha@ubi.pt \\ (iD) http://orcid.org/0000-0003-4890-7931
}

Fecha de recepción del artículo: 01/09/2019

Fecha de aceptación definitiva: 24/10/2019

\begin{abstract}
RESUMO
Muitas seriam os casos de estudo interessantes para várias reflexões sobre várias questões, mas optamos por conhecer com maior detalhe o percurso de três jovens artistas portugueses que tem posto em diálogo a linguagem cinematográfica com a arte contemporâneo, explorando as relações múltiplas entre a sala de cinema e a galeria de arte. Pela projecção internacional da sua obra e pela complexidade do seu trabalho, mas também pela maior facilidade de acesso às suas obras, escolhi debruçar-me sobre os casos de Gabriel Abrantes, Filipa César e Salomé Lamas, sabendo que muitos outros aspectos ficariam, de certa forma, colocados em plano paralelo ou secundário.

Palavras chave: Cinema português; Cinema expandido; Gabriel Abrantes; Filipa César; Salomé Lamas.

ABSTRACT

It would be very interesting case studies for various reflections on various issues, but we chose to know in more detail the path of three young Portuguese artists who have put dialogue between film language and contemporary art, exploring the multiple relationships between the cinema and the art gallery. Because of the international projection of his work and the complexity of his work, but also the easier access to his works, I chose to look into the cases of Gabriel Abrantes, Filipa César and Salomé Lamas, knowing that many other aspects would be, in a way, placed in parallel or secondary plane.
\end{abstract}

Key words: Portuguese Cinema; Expanded Cinema; Gabriel Abrantes; Filipa César; Salomé Lamas.

\section{Introducción}

No início dos anos 80, num período de forte internacionalização do cinema português no contexto europeu, onde se sucederam prémios importantes e um reconhecimento crítico inédito, Portugal começou a ser visto como um espaço cinematográfico 
de "origem demarcada", com uma forte matriz identitária. Durante os anos 80 e 90, a designada Escola Portuguesa apresentava um conjunto de características formais e estéticas que ganhavam coerência nas obras de Manoel de Oliveira, António Reis e Margarida Cordeiro, João César Monteiro, Teresa Villaverde, João Mário Grilo e João Botelho, apenas para citar alguns nomes. A reflexão meta-cinematográfica sobre uma condição histórica e cultual, uma suposta identidade portuguesa, serviam de mote para pensar o país num momento de integração europeia. A cinematografia portuguesa, pouco expressiva do ponto de vista quantitativo, face a diversas contingências económicas, foi conquistando o seu espaço num circuito de produção e reconhecimento crítico de prestígio.

Gradualmente, esse corpo nuclear de autores foi-se diversificando, abrindo espaço à afirmação de novos valores que, se por um lado, se inscreviam nessa tradição, por outro, queriam romper com os cânones estabelecidos nas décadas anteriores. Essa lenta mudança de paradigma foi sendo alimentada por vários autores, a maioria deles em permanente diálogo com outras formas de expressão. Há o caso de cineastas que mantém uma actividade paralela do seu trabalho noutras áreas, como o veterano Jorge Silva Melo, que fundou a Cornucópia (1973-2016) e os Artistas Unidos (1995-) e mantém uma carreira de encenador e dramaturgo desde a década de 1970; ou o caso de Gonçalo Tocha, que mantém uma interessante carreira musical no projecto TochaPestana desde 2004; ou o fotógrafo Daniel Blaufuks, que mantido um percurso cinematográfico (Sob Céus Estranhos, 2002; Um pouco mais pequeno que o Indiana, 2006, Éden, 2011) paralelo aos trabalhos na fotografia. Existem vários casos de artistas de outras formas de expressão artística que tem trabalhado recorrentemente com cinema: o artista plástico Pedro Bastos tem desenvolvido uma interessante carreira cinematográfica (Ao Lobo da Madragoa, 2012; Cabeça de Asno, 2016; Ambulatório através da poesia de Augusto dos Santos e António Nobre, 2019), sempre num diálogo efervescente entre várias formas de expressão artística; o músico Paulo Furtado (The Legendary Tigerman), com uma longa carreira na música indie rock começou por realizar alguns dos seus vídeo musicais (ou em colaboração com Rodrigo Areias), mas que tem experimentado também a ficção (Amor Quântico, 2019) e a performance (Paleface, na Solar); o fotógrafo João Tabarra também foi adoptado o vídeo como meio privilegiado no seu trabalho (Mute Control, 2000, em Serralves; Barricades improvisés, 2001); e o mesmo se passa com o artista visual João Onofre, que tem criado diversos trabalhos em vídeo para exposições individuais e colectivas.

Por outro lado, nas últimas duas décadas, de forma mais recorrente, e à semelhança do que acontece em várias cinematografias de dimensão reduzida, a procura de meios alternativos de produção e circulação "empurraram» ou "desviaram» para espaços alternativos diversos cineastas. Em Portugal, registam-se várias incursões de cineastas com carreiras estabelecidas na área do cinema a fazer incursões por outras formas de expressão artística: Marco Martins encenou as peças de teatro Estaleiros (2012), Great Yarmouth (2017) Actores (2017) ou Provisional Figures (2018); João Botelho já encenou a ópera Banksters (2011) no Teatro São Carlos, em Lisboa. Finalmente, em ocasiões particulares, cineastas promovem encontrou dos seus filmes com outras formas de apresentação pública, por exemplo: João Pedro Rodrigues e João Rui Guerra da Mata conceberam, para a Solar - Galeria de Arte Cinemática de Vila do Conde, a exposição Do Rio das Pérolas ao Ave (2016);

Estes diversos trabalhos são representativos de uma vitalidade intermediática e intertextual que tem caracterizado o cinema português contemporâneo. Muitas seriam 
os casos de estudo interessante para várias reflexões sobre várias questões, mas optamos por conhecer com maior detalhe o percurso de três jovens artistas portugueses que tem posto em diálogo a linguagem cinematográfica com a arte contemporâneo, explorando as relações múltiplas entre a sala de cinema e a galeria de arte. Pela projecção internacional da sua obra e pela complexidade do seu trabalho, mas também pela maior facilidade de acesso às suas obras, escolhi debruçar-me sobre os casos de Gabriel Abrantes, Filipa César e Salomé Lamas, sabendo que muitos outros aspectos ficariam, de certa forma, colocados em plano paralelo ou secundário. O texto é essencialmente um convite para um primeiro contacto com as obras destes três estimulantes casos de estudo, na expectativa que possa despertar a curiosidade do leitor e que o leve a ver as obras e a conhecer melhor estes e outros autores.

\section{Gabriel Abrantes}

Gabriel Abrantes nasceu em 1984, em Chapel Hill, no estado da Carolina do Norte, nos Estados Unidos da América. Vindo das artes plásticas, mas com formação académica em cinema e artes visuais, Gabriel Abrantes começou por fazer cinema em contexto de galeria, realizando e produzindo filmes essencialmente para serem exibidos em exposições de artes plásticas. No entanto, desde cedo começou a construir um universo estético muito singular no contexto do cinema português contemporâneo. A obra fílmica de Gabriel Abrantes iniciou-se em 2006 com a produção de vários pequenos filmes que integravam exposições de artes plásticas do autor, mas gradualmente foi-se encaminhando para processos produtivos mais próximos do cinema e procurando enquadrar-se no circuito cinematográfico, particularmente no circuito dos festivais de cinema. Apesar desta aproximação processual, Gabriel Abrantes (Marmeleira, 2010: em linha) rejeita ser classificado apenas como um cineasta: "Quero fazer cinema, mas vejo-me como um artista [...] Não como pintor, escultor, fotógrafo ou cineasta. Sou um artista que está a trabalhar em diversos meios.»

De acordo com Alexandre Melo (cit. in Abrantes, 2010: 110)., crítico e pontual colaborador de Abrantes, as obras Dear God please save me (2006), Anarchist King (2006), The Razor thin definition of Punk (2006), Arabic Hare (2006), Tunel Performance (2006) e Gugg ' $n$ ' Tate (2008) incluem-se nos "trabalhos escolares", que se distinguem da restante obra de Gabriel Abrantes, «antes de mais, pelo seu afastamento em relação a temáticas que dizem respeito à história da arte, às instituições do mundo da arte contemporânea e ao modo como com elas se relacionam os jovens artistas». Gabriel Abrantes (2010: 294) corrobora com esta análise, afirmando que estas obras focavam «questões relacionas com a crítica institucional do mundo da arte: a função/ economia do mundo da arte, a forma da arte, o questionamento da representação como tema."

A transdisciplinaridade é, naturalmente, uma característica muito cara a Gabriel Abrantes. O jovem autor afirma que trabalha em diversas plataformas porque acredita que «o conceito ou ideia é a parte mais importante ou valiosa de qualquer trabalho e é transferível entre plataformas». O que realmente lhe interessa "é a narrativa, que pode ir desde a escultura até ao cinema, bem como à vida. A criação de objetos úteis, sejam filmes, pinturas ou concertos, é a [sua] principal intenção» (Abrantes cit. in Marques, 2009: em linha). Ainda a este propósito, ao programa Fotograma, da televisão pública 
portuguesa (2009: em linha), Gabriel Abrantes explicava que não considerava haver diferenças significativas entre as suas pinturas, filmes e fotografias.

Alexandre Melo (cit. in Abrantes, 2010: 110) prefere classificar o cinema de Abrantes como «exemplo de um dilema de localização disciplinar: entre o mundo da arte contemporânea e o mundo do cinema [...] O autor não faz apenas filmes. Fez e faz também fotografia, pintura sobre tela, trabalhos sobre papel (desenhos, aguarelas), esculturas [...] e instalações que, em muitos casos, criam o contexto especial para a projeção de filmes".

Visionary Iraq (2008) e Too many Daddies, Mommies and Babies (2009) foram produzidos precisamente nesse referido contexto de instalações: o primeiro filme foi produzido para integrar a exposição homónima apresentada na Galeria 111, no Porto; e o segundo foi o resultado de três exposições em três espaços distintos da cidade de Lisboa (Museu da Eletricidade - espaço institucional; Galeria Zé dos Bois - espaço de residências artísticas; e Lumiar Cité Escola Maumaus - espaço expositivo num bairro social), em que cada um dos espaços que serviram, cada um destes, comode cenário à rodagem de cada uma das três partes do filme. Para o efeito, e foram transformados em instalação e utilizados como espaços de exibição do próprio filme. Segundo o próprio Abrantes (2010: 294), estes filmes iniciais "relacionam-se diretamente com a forma como estes espaços [galerias de arte e espaços de arte institucionais] funcionam. As estruturas das narrativas, a teatralidade dos cenários e a relação com o espaço de exposição foram elementos que estruturaram a dinâmica do trabalho».

Para uma análise à primeira fase da obra de Gabriel Abrantes é muito útil convocar o conceito de "cinema expandido", que se refere ao cinema produzido para ser exibido fora do espaço histórica e socialmente convencionado (sala de cinema). Parece-me claro considerar que o modo de exibição - projeção fragmentada por múltiplos espaços, ausência ou desvalorização da linearidade narrativa, coexistência com outras peças artísticas não-fílmicas, manipulação do tempo pelo próprio espectador, entre outros - influencia objetivamente o modo de produção. A espaços, este dispositivo próprio do "cinema expandido" parece muito próximo do "cinema das atrações», onde a narrativa linear e a tradicional lógica de causa-efeito perdem relevância, porque mais importante do que contar uma história é mostrar momentos de uma história, momentos marcantes que se justificam mais pelo aspeto visual do que racional, procurando-se que essas imagens possam provocar reações emocionais no espectador.

Christopher Kihm (cit. in Abrantes, 2010: 12) designa o cinema de Abrantes como "arcaico", explicando: "Dada a abundância de afiliações e de orfandades, estabeleceu-se um novo território para o cinema, onde as formas não se desenvolverão através de novas alianças ou heranças, mas antes através de um novo arcaísmo». Ainda a propósito desse "cinema arcaico", Kihm conclui: "O cinema arcaico de Gabriel Abrantes é um laboratório de lugares comuns (étnico, social, político, cultural ou artístico), e isso demonstra, através de deslocamentos e redistribuições, como é possível tecer novas histórias, definir novos problemas e delinear novas verdades» (ibidem: 24).

E concretiza o seu raciocínio com o exemplo de Olympia I (2006) e Olympia II (2006), que considera "O primeiro filme» realizado pelo autor. Gabriel Abrantes correalizou e coprotagonizou com Katie Widloski um díptico inspirado no quadro homónimo do francês Édouard Manet (1832-1883), pintado em 1863 e considerado «imoral» na época, e num ensaio fotográfico publicado na revista Vogue sobre outro trabalho de Manet, o Dejeuner sur l'Herbe. Basicamente, o quadro de Manet retrata uma jovem nua deitada com vários pormenores que a podem identificar como uma 
cortesã da alta sociedade acompanhada por uma empregada negra com um ramo de flores. As versões de Abrantes contam duas histórias distintas: «Uma prostituta é visitada pelo irmão adolescente homossexual e os seus dois cães. Ele confronta-a sobre a forma de ela viver depois de ter jogado Trivial Pursuit com a mãe no pátio. Ele não pagaria um cêntimo pelas suas mamas nojentas.»; "Um prostituto travesti de uma família de classe média do Texas espera clientes enquanto ouve Henry Gorecki e bebe uma mini Coca-Cola diet. A sua empregada, a 'morango com cobertura de chocolate', tenta acalmá-lo, apalpando-lhe o 'material', e os dois começam a fazer amor» (JFlor, 2011: em linha).

Mais do que pela reprodução, as versões de Abrantes são marcadas pelo cruzamento de referências clássicas com outras contemporâneas, adaptando a composição à realidade norte-americana, denunciada por várias referências linguísticas, geográficas e históricas inequívocas. De forma provocatória, o realizador parece mesmo brincar com significados simbólicos das referências usadas, como o facto de a escrava negra ser interpretada por Katie Widloski pintada com uma tinta negra.

As múltiplas referências artísticas são um elemento fundamental na leitura e na compreensão do trabalho de Abrantes. Se em Olympia I e Olympia II a referência matricial é a pintura, a literatura é referencial em Palácios de Pena, o teatro em Fratelli e Zwazo, e o próprio cinema, nomeadamente os subgéneros da ficção científica e do filme-catástrofe em Too many Daddies, Mommies and Babies, o melodrama e o filme de guerra em Visionary Iraq e o meta-filme em 2002, 2003, 2004.. 2002.

\section{Filipa César}

Filipa César nasceu no Porto, em 1975, e é formada em Pintura pelas faculdades de Belas Artes do Porto e de Lisboa, Filipa César concluiu o mestrado Art in Context na UDK (Universidade das Artes de Berlim) em 2008. Nessa altura, havia já começado a incorporar o cinema na sua obra, nomeadamente como suporte instalativo, interessando-se sobretudo por reflectir sobre os dispositivos de produção e recepção da imagem nas sociedades contemporâneas.

José Marmeleira (2010b, em linha) destaca precisamente, nas primeiras obras, a "presença de elementos e referências do universo e da linguagem do cinema: a ficção e a ideia de montagem. Recorde-se Untitled (Twirler), de 1999, vídeo onde uma sequência de quartos e salas vazios (aparentemente apropriados de filmes de acção ou terror) suspendia um desfecho sempre frustrado, ou Letters (2000), que encenava uma série de diálogos, conversas e encontros em balcões dos correios.» Filipa César reconhece que foi na Alemanha, onde se radicou a partir de 1998, que o seu interesse pelo cinema se tornou mais consciente, graças à "descoberta de uma abordagem mais experimental do documentário: Alexander Kluge, Fassbinder, Harun Farocki, Robert Frank, Ivonne Rainer, Babette Mangolte, Frederick Wisemann» (ibidem). Nas suas primeiras obras audiovisuais, a imagem em movimento não surge apenas como um suporte de projecção, mas também assume uma forma reflexiva, assumindo uma performatividade que vai alternando da montagem para a mise-en-scéne.

A primeira exposição individual de Filipa César aconteceu na Solar - Galeria de Arte Cinemática, em Vila do Conde, entre Outubro e Dezembro de 2010. Essa exposição intitulada Montage integrava uma série de vídeos e instalações produzidas entre 2007 e 2010, nomeadamente The Four Chamered Heart (2009, Galeria Cristina 
Guerra, Lisboa) que propõe uma pertinente reflexão metacinematográfica ao colocar em diálogo estudantes de cinema palestinianos e judeus após o visionamento do La Pyramide Humaine (1961) de Jean Rouch, experiência mediada por uma série de cadeiras que sublinhava a imobilidade do espectador durante o visionamento. Também metacinematográfica é a reflexão presente em F for Fake (2005), um vídeo realizado a partir de imagens do filme homónimo de Orson Welles de 1973 que integrava uma instalação, na Galeria Cristina Guerra, em Lisboa, feita com três mil cassetes VHS (que formavam a letra F) e cinco fotografias de grande formato. A Solar apresentou ainda Le Passeur (2008, Fundação Ellipse, Estoril), que incluía duas projecções impossíveis de ver ao mesmo tempo: "para mim essa forma foi necessária para aquilo que eu queria, que era falar sobre as passagens, sobre o cinema como uma forma de passagem, e ao mesmo tempo sobre o lado secreto que está envolvido nas passagens. Portanto, ou víamos o rio ou víamos os passadores a falar. A própria experiência no espaço implicava qualquer coisa que ficava sempre oculta.» (Filipa César cit. in Mourinha, 2018, em linha). Finalmente, a exposição na Solar incluiu ainda Memograma (2010, Museu Berardo, Lisboa), uma instalação que incluía dois vídeos e uma série de fotografias sobre o processo de censura em Portugal do filme As Lágrimas Amargas de Petra von Kant (1972), de Rainer Werner Fassbinder. Um dos vídeos apresenta depoimentos de várias pessoas em Castro Marim, cidade de fronteira que foi lugar de exílio para mulheres homossexuais durante o Estado Novo, e o outro descreve a história e memória desse mesmo lugar no contexto português.

Mais do que filmes isolados, que podem ser projectados numa qualquer sala de cinema convencional, Filipa César pensou estas imagens em movimento para espaços específicos, com condições de visionamento ou de apresentação que proporciona experiências diferentes: "Com a instalação é possível um tempo diferente, um outro relacionamento com a imagem em movimento e uma autonomia. O espectador move-se e os fotogramas sucedem-se. Os encontros que daí resultam são mais inesperados.» (Filipa César cit. in Marmeleira, 2010, em linha).

Ainda em 2010, Filipa César filmou Porto, 1975, uma encomenda para integrar a participação portuguesa na $12 .{ }^{a}$ Bienalle di Venezia, onde a artista portuense visita o complexo habitacional social da Bouça, na cidade do Porto, e todo o complexo contexto da sua implementação, nomeadamente o período pós-revolucionário e o projecto SAAL (Serviço Ambulatório de Apoio Local), que constituiu-se como uma experiência pioneira no contexto europeu que promovia o contacto entre equipas de arquitectos com populações desfavorecidas em processo de construção de habitações sociais).

Em 2009, uma passagem pelo Colonial Film Project, em Londres, iria estar na origem de um projecto ambicioso e complexo: Luta ca caba inda (A Luta ainda não acabou) propunha recuperar a totalidade do arquivo fílmico da Guiné-Bissau, através de um processo de digitalização do material então existente. Ao longo de aproximadamente uma década, Filipa César recuperou as imagens possível e reunir uma série de objectos raros que ajudam a contextualizar o arquivo e o seu próprio projecto de pesquisa. Spell Reel, o filme-resumo do projecto foi lançado em 2017 documenta parte do processo criativo e produtivo, como as inúmeras performances que foram sendo apresentadas em várias geografias.

Ao longo do projecto Luta ca caba inda, Filipa César foi concluindo diversos filmes, produzidos ao abrigo de dois programas, o Living Archive (2011-13) e o Visionary Archive (2013-15), ambos organizados pelo Arsenal - Institute for Film and Video 
Art, Berlim: Cacheu (2012) foi filmado durante um congresso em Berlim (What happened 2081?, com curadoria de Georg Diez e Christopher Roth), e regista uma performance de Joana Barrios perante uma plateia de participantes reunidos no Kunst-Werke Institute for Contemrorary Art. Cuba (2012) foi filmado na mesma cidade alemã (agora no FEZ-Berlin), com a mesma Joana Barrios (acompanhada pelos guineenses Suleimane Biai e Carlos Vaz), mas agora para o programa Satellite do Museu Jeu de Paume, em Paris. Finalmente, ainda em Berlim (Reboot.fm studio e House of the Worls Cultures), Conacry (2012) apresenta performances de Grada Kilomba e de Diana McCarty. Mined Soil (2014) resulta do trabalho desenvolvido na preparação de uma série de apresentações ao vivo que foram sendo realizadas entre 2013 e 2014 em várias cidades europeias (Roterdão, Holanda; Antuérpia e Bruxelas, Bélgica; Paris, França; Limerick, Irlanda; Lisboa, Portugal; e Madrid Espanha). Conduzido pela própria Filipa César, este vídeo junta diversos materiais recolhidos durante o processo de investigação de Filipa César e Natxo Checa, desde textos de Amílcar Cabral, Walter Benjamin ou Kwame Nkrumah e outros objectos e imagens (como as captadas no arquivo geológico da Boa Fé, no Alentejo). Finalmente, a obra Transmissions from the Liberated Zones (2016), apresentada por Gi Dias, é mais um exercício performativo que inclui depoimentos de um grupo de suecos (o cineasta Lennart Malmer, a política Birgitta Dahl, a psicóloga e cineasta Ingela Romare e o diplomata Folke Lofgren) que filmaram a Guiné Bissau nos anos 70, nomeadamente as zonas libertadas pelo PAIGC (Partido Africano para a Independência da Guiné-Bissau e Cabo Verde) ao domínio colonial português.

Ainda que sejam exibidos em salas de cinema convencionais (por exemplo: Cuba e Transmissions from the Liberated Zones estrearam no festival de cinema Berlinale; Cacheu foi exibido nos festivais de Oberhausen e Torino; Mined Soil estreou mundialmente no festival de Roterdão e foi premiado no Curtas Vila do Conde; e Spell Reel teve exibição comercial nas salas portuguesas), estas obras foram concebidas como acontecimentos instalativos. Ainda assim, os filmes resultantes dessas experiências são mais do que meros registos audiovisuais, assumindo, pela montagem ou pela mise-en-scène, formas de narrar através do espaço e da performatividade. Quando exibidos no seu espaço natural, geralmente galerias, as obras fílmicas são acompanhadas por diversos materiais que ajudam a contextualizar as imagens e os sons ou que expandem as possíveis leituras.

\section{Salomé Lamas}

Salomé Lamas nasceu em Lisboa, em 1987, e estudos cinema na Escola Superior de Teatro e Cinema do Instituto Politécnico de Lisboa e na FAMU, em Praga, na Republica Checa, e concluiu um MFA em Artes Visuais no Sandberg Instituut, Gerrit Rietveld Academie, em Amsterdão, Países Baixos. Actualmente frequenta o curso de doutoramento em Arte Contemporânea da Universidade de Coimbra. Desde 2008, Salomé Lamas tem apresentado um intenso e surpreendente ritmo de criação e produção em vários suportes e plataformas, cruzando o cinema e as imagens em movimento por espaços como a galeria e a academia.

As primeiras obras - O Palimpsesto da Rapariga Cisne ou choveu bastante durante dois dias e a paisagem alterou-se (2008), Jotta: A Minha Maladresse é uma forma de Delicatesse (2009), Imperial Girl (2010), Golden Dawn (2011), VHS - Video Home System (2010-2012) - anunciam uma vertigem criadora de Salomé Lamas, onde a autora 
parece apresentar e explorar dimensões documentais complexas com dispositivos que parecer simplificar a realidade. Gradualmente, a autora transita para um dispositivo "paraficcional", onde procura fugir às fronteiras convencionais que pretendem catalogar as imagens (e que geralmente separa ficção e documentário), afirmando uma transversalidade que não convive com essas categorias. O ponto de viragem aconteceu em 2012, com Encounters with Landscape (3x) (2012), A Comunidade (2012) e Terra de Ninguém (2012), produções aparentemente mais convencionais do ponto de vista cinematográfico que fizeram percursos surpreendentes nas salas de cinema, primeiro em festivais de prestígio e também no circuito comercial. Estes trabalhos usam os métodos mais convencionais da categoria documental para a desconstruir.

A par de uma produção cinematográfica, Salomé Lamas foi também usando o suporte cinematográfico e videográfico para conceber instalações intermediais, apelando a vários sentidos do espectador e explorando as várias dimensões sensoriais: 11 heatrum Orbis Terrarum (2013), uma vídeo-instalação apresentada no Museu Nacional de Arte Contemporânea (Museu do Chiado, Lisboa, Portugal): a instalação Norte (2015), com colaboração de Filipe Felizardo na performance audiovisual com música ao vivo, apresentada em vários espaços nacionais e internacionais e agora integra a Coleção António Cachola (Lisboa): em 2017 desenvolve a obra Ubi Sunt, um projecto híbrido e ecléctico que inclui as performances One Life to Live e Requiem do artista alemão Christoph Both-Asmus, desenvolvida no Centro Educativo de Santo António, na cidade do Porto, e que seria sucedido pelas obras Ubi Sunt II (2017) e Ubi Sunt III (2017, em três canais vídeo), ambas com a colaboração de Christoph Both-Asmus; The Buriel of the Dead (2016), uma instalação de vídeo em três canais comissariada pela suiça Biennale of Moving Images; a instalação-gravura Self Portrait (2016-17), desenvolvida durante uma residência artística na Solar - Galeria de Arte Cinemática, em Vila do Conde, que integra duas foto-gravuras em suporte web; Horizon Noziroh (2017), em colaboração com Gregorio Graziosi e Christoph Both-Asmus, com o apoio do CPH:DOC e o instituto de cinema da Dinamarca; ...Riots and Rituals (2016), uma instalação web vídeo (122 gif) encomendada pela espanhola Tabakalera Centro Internacional de Cultura Contemporanéa.

A experimentação e intersecção de linguagens e plataformas tem sido desenvolvida de forma sistemática por Salomé Lamas, que se recusa a ficar "aprisionada" a convenções específicas de cada campo de acção, explorando as potencialidades transdisciplinares e intermediais. Le Boudin (2014) é uma espécie de díptico, que estreou na versão filme no Curtas Vila do Conde e na versão vídeo-instalação na Fundação Calouste Gulbenkian (Lisboa). O mesmo processo aconteceria com A Torre (2015, em colaboração com Christoph Both-Asmus), que teve uma versão para salas de cinema, com estreia no Curtas Vila do Conde e exibições nos prestigiados FID Marseille e Oberhausen, e uma versão instalativa que foi apresentada no Museu de Arte Arquitectura e Tecnologia (Lisboa) e no Centre National de Arts Plastiques (Paris). Eldorado XXI (2016), talvez o filme da autora com mais prémios no circuito de festivais (Melhor Documentário no Festival de Cinema de Lima, no Perú, Melhor Film no Pancevo Film Festival, na Sérvia, Menção Especial do Júri no FINUCAM, o México, e Melhor Filme no Porto/Post/Doc, em Portugal), seria acompanhado pela vídeo-instalação Mount Anenea (5853) (2015, com colaboração de Bruno Moreira, Norberto Lobo e João Lobo), que esteve patente ao público no Museu de Arte Contemporânea de Serralves (Porto) e na Galeria Miguel Nabinho (Lisboa). Também Extinção (2018), que foi exibido em vários festivais internacionais de cinema (Festival du Réel, DocLisboa), e 
que teve estreia comercial em salas de cinema portuguesas e britânicas, acabaria por ter uma versão vídeo-instalativa, patente no Museu do Chiado.

As obras da autora começam a ser concebidas, de forma mais complexa e ambiciosa, como projectos intermediáticas desde a raiz, pensando na sua expansão para diversas modalidades que acabam por se complementar: entre 2016 e 2019, a artista tem desenvolvido o projecto Fatamorgana, que inclui, para já, uma peça de teatro, dois filmes (Fatamorgana e What do we talk about when we talk about Fatamorgana), duas publicações e uma instalação sonora (Affektenlebre, em colaboração com Miguel Martins). Actualmente, entre outros trabalhos, desenvolve também o projecto Extraction: The Raft of the Medusa, que tem previsto apresentar dois filmes, uma instalação e uma publicação.

Mesmo com o sucesso alcançado no meio cinematográfico - Encounters with Landscape (3x) (2012) foi premiado no IndieLisboa; A Comunidade (2012) venceu o prémio para Melhor Documentário no Curtas Vila do Conde; Terra de ninguém (2012) venceu Melhor Longa Portuguesa no DocLisboa e uma menção especial do DocumentaMadrid - Salomé Lamas mantém uma intensa actividade permanente no meio das galerias de arte, como atesta o tríptico Hangar-Terminal-Metro (2018), que junta três vídeos e foi comissariado pela representação portuguesa na La Biennale di Venezia - Architettura.

Em 2017, numa entrevista a um jornal português, Salomé Lamas reconhecia que gosta da «ideia do realizador como alguém que traduz, que transporta a linguagem das coisas na linguagem cinematográfica. E, para a tradução ser boa, não vai dizer o mesmo que o original. Vai ser autónoma.» (Salomé Lamas cit. in Marques, 2017, em linha). A complexidade da "tradução» da realidade será a melhor justificação para a multidisciplinaridade e intermedialidade da sua obra, que se multiplica pelos recursos e discursos disponíveis. Por outro lado, essa vontade de traduzir a realidade tem levado Salomé Lamas a viajar por várias partes do mundo, pelas regiões mais recônditas e ignoradas, com particular atenção pelos lugares historicamente mais reprimidos, marginalizados e ignorados: Eldorado XXI mergulha na realidade das árduas condições de vida dos mineiros em La Rinconada, a povoação mais alta do mundo (5100 metros de altitude), nos Andes peruanos; a incógnita Transnístria, país que reclama a independência há décadas, "preso» entre a fronteira da Rússia, Ucrânia, Bulgária, Moldávia e Roménia, é o tema central de Extinção; Fatamorgana ambienta-se em Beirute, acompanhando a vida da jovem Hana e do complexo contexto político e social do Líbano.

Estas obras são resultado de várias residências artísticas desenvolvidas pela artista, que assim vai conhecendo as diversas realidades que vai traduzindo, com um método de pesquisa e de criação próximo do preconizado pelos cineastas-antropólogos do Sensory Etnography Lab, da Universidade de Harvard, nos Estados Unidos da América, um laboratório que promove combinações inovadoras entre estética e etnografia, usando diversas formas de materialidades (filme, vídeo, fotografia, instalação, fonografia performance) para explorar a estética e a ontologia do mundo não-natural, ou seja, para traduzir a experiência humana apelando aos vários sentidos. Cada «realidade» é composta por diversas camadas específicas e cabe à autora usar os meios ao seu dispor para traduzir da melhor forma essa realidade, transmitindo ao espectador a mais complexa experiência. 


\section{Epílogo}

Estes três percursos aqui abordados, diferentes propostas de «expansão» de formas e de territórios ao cânone mais tradicional do cinema português, são exemplares de uma marcada tendência no cinema português do séc. XXI, uma forma de expressão que sobrevive com enormes constrangimentos e dificuldades num país pouco sensível a políticas públicas para o cinema, e para as artes em geral. A insensibilidade politica tem tido como resposta uma procura de novos meios de financiamento e de formas alternativas de produção e circulação, condições que tem proporcionado uma gradual transformação dos meios de produção no cinema português. Também as mais recentes formas de valorização, seguindo tendências que promovem a intertextualidade e intermedialidade, tem permitido o surgimento de canais de exibição transversais a outras práticas artísticas que se situam fora das salas de cinema convencionais, como galerias de arte, centros culturais, eventos científicos, entre outros. Os modos de produção do cinema independente tem-se adaptado aos vários constrangimentos do mercado, e o cinema português tem tentado também expandir-se dos meios mais convencionais como uma forma de dar respostas às crescentes necessidades. Consequentemente, estes novos projectos criativos e produtivos tem contribuído para uma redefinição do cinema português no séc. XXI, uma mudança que beneficiou da transição para um paradigma tecnológico assente no digital e na intermedialidade.

De uma forma natural, estes três casos de estudo do cinema expandido português do séc. XXI apresentam como característica comum um afastamento da "realidade» portuguesa, uma forte matriz que marcou identitariamente o cinema português das últimas décadas: Gabriel Abrantes, nascido nos Estados Unidos, interessa-se muito pelas polifonias da geopolítica mundial, explorando fenómenos da globalização, da geopolítica internacional, das novas identidades culturais, do sentimento de culpa histórica, dos movimentos migratórios ou da economia global atual (filma na Amazónia, Haiti, Angola, etc.); Filipa César tem trabalhado com o arquivo cinematográfico da Guiné-Bissau, país africano colonizado por Portugal e protagonista de uma dos mais violentos conflitos armados anti-coloniais dos anos 60-70, precisamente contra o colonizador português, que causou traumas nas das sociedades que as mantiveram de costas voltadas durante as décadas seguintes; Salomé Lamas também tem viajado para regiões historicamente reprimidas, marginalizadas e ignoradas (La Rinconada ou Transnístria) para desenvolver os seus projectos artísticos. As gerações de cineastas que se tem revelado no séc. XXI têm vindo a contestar e a romper, de forma mais ou menos declarada, com o património matricial do cinema português das duas últimas décadas do séc. XX, nomeadamente a chamada "Escola Portuguesa» e a sua obsessão autorreferencial por pensar a história, memória e cultura colectiva da nação portuguesa. O cinema expandido tem contribuído para esse movimento internacional, de olhar o mundo e de dialogar com questões transversais a outros contextos civilizacionais.

Por outro lado, as novas gerações, que tem desenvolvido actividade sobretudo depois de 2001, tem-se formado em diversas instituições de ensino, em áreas artísticas próximas mas distintas da linguagem cinematográfica convencional. Durante décadas, o ensino do cinema passou tendencialmente pela Escola Superior de Teatro e Cinema (fundada em 1973), uma instituição de ensino central onde foram formados os principais cineastas de referência das décadas de 1990-2000, como Pedro Costa, João Pedro Rodrigues ou Miguel Gomes. No entanto, a recente proliferação de cursos superiores 
de cinema e audiovisual, belas artes, artes plásticas, artes visuais, arquitectura, fotografia, artes digitais, entre outros, tem contribuído para uma renovação significativa da forma de pensar e fazer cinema em Portugal. Por isso mesmo, a par da galeria de arte, a academia tem sido um eixo fundamental na "expansão" do campo cinematográfico português. Importa sublinhar que estes três autores portugueses foram formados em áreas científicas que trabalham com a imagem mas com processos e métodos muito distintos da prática cinematográfica clássica, marcando também uma ruptura com uma tradição pedagógica muito dependente da linguagem cinematográfica.

À semelhança do que tem vindo a acontecer com outras cinematografias de pequena e média dimensão, o cinema expandido português tem conquistado maior visibilidade nos circuitos internacionais e, consequentemente, mais espaço no meio cinematográfico português. De uma prática pontual de alguns artistas mais inventivos, o cinema expandido tem consolidado o seu espaço próprio de existência. Em suma, o cinema expandido produzido em Portugal nas últimas duas décadas tem tudo uma importância, muitas vezes desvalorizada e ignorada, na própria identidade do cinema português, abrindo os seus horizontes a novas práticas produtivas e criativas.

\section{Bibliografía}

Abrantes, Gabriel (ed.) (2010). And I am so thankful for all the friendships $i$ have made. Films by Gabriel Abrantes and in collaboration with Benjamin Crotty, Daniel Schmidt and Katie Widloski. Guimarães: Centro Cultural Vila Flor.

Cunha, Paulo (2013). Gabriel Abrantes: o contador de estória. En Pereira, A. C. \& Cunha, T. C. (eds.). Geração Invisivel: Os novos cineastas portugueses (267-286). Covilhã: Labcom/UBI.

Cunha, Paulo (2016). Luta ca caba inda: repensar o arquivo, a história e a memória na Guiné-Bissau através do trabalho de Filipa César. Estudos Linguísticos e Literários, 53, 222-240. doi: http://dx.doi.org/10.9771/2176-4794ell.v0i53.15857.

JFlor (2009). Gabriel Abrantes. Arte Facto, 20 de setembro. Recuperado en http://arte-factoheregesperversoes.blogspot.pt/2011/09/gabriel-abrantes.html

Marmeleira, José (2010). O cinema impuro do artista Gabriel Abrantes. Público, 8 de setembro. Recuperado de http://ipsilon.publico.pt/artes/texto.aspx?id=264748.

Marmeleira, José (2010b). Filipa César e os fantasmas no presente. Público, 3 de março. Recuperado de https://www.publico.pt/2010/03/03/culturaipsilon/noticia/filipa-cesar-e-os-fantasmas-no-presente-251897

Marques, Pedro (2009). Gabriel Abrantes segue os passos de Herzog! Rua de Baixo, 3 de abril. Recuperado en http://www.ruadebaixo.com/gabriel-abrantes.html

Marques, Susana Moreira (2017). Salome Lamas: Gosto da ideia do realizador como alguém que traduz». Jornal de Negócios. Recuperado de http://www.jornaldenegocios.pt/weekend/ detalhe/salome-lamas-gosto-da-ideia-do-realizador-como-alguem-que-traduz

Mourinha, Jorge (2018). Filipa César, a investigadorfa das imagens perdidas. Público, 22 de Junho. Recuperado de https://www.publico.pt/2018/06/22/culturaipsilon/entrevista/a-investigadora-das-imagens-perdidas- 1834478 